
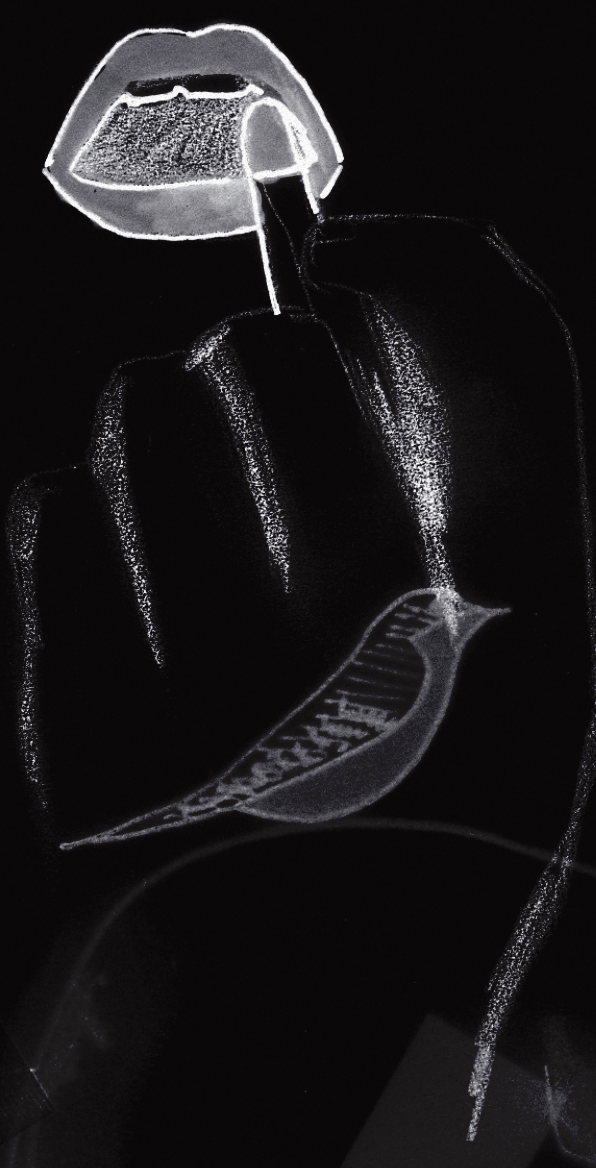
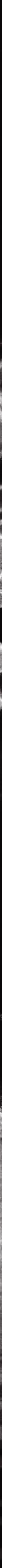


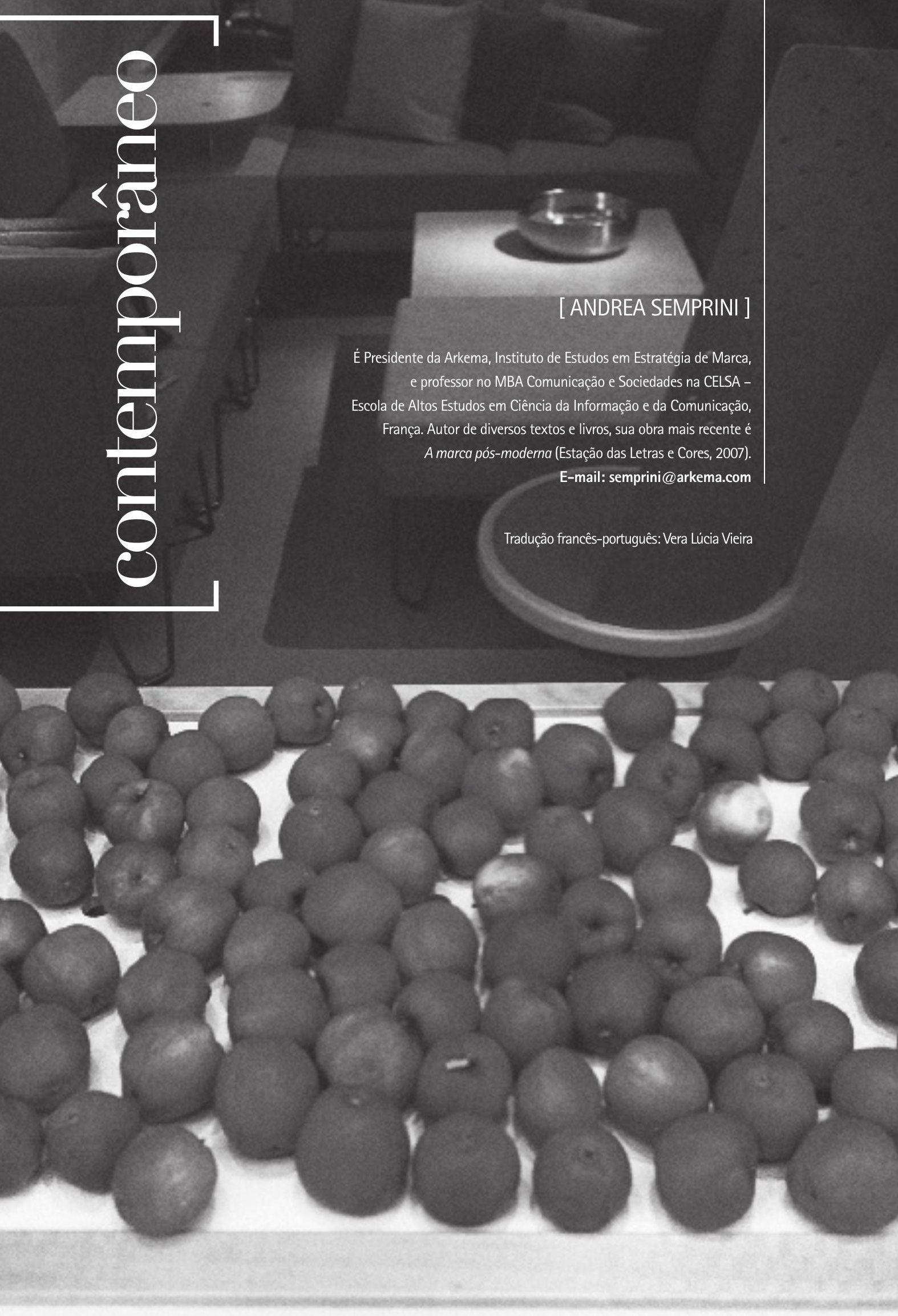

\section{Marca e ponto-de-venda retomada do diálogo}


As marcas vivem há alguns anos um estranho paradoxo: nunca elas foram tão poderosas e tão atacadas. Ainda que seu poder financeiro e comercial tenha atingido níveis desproporcionais, o horizonte que cerca o assunto está, ainda, repleto de nuvens. Os consumidores mostram-se cada vez mais exigentes, até mesmo críticos em relação às marcas, quando não voltados categoricamente para os macrodescontos. De forma mais ampla, assistimos a uma crescente crítica social das marcas, catalisada pelo livro de Naomi Klein, No logo. Sob vários pontos de vista, a relação entre as marcas e os consumidores deteriorou-se, tornou-se mais abstrata, mais distante. Além disso, a multiplicação de manifestações das marcas e a forte pressão publicitária engendraram uma sensação de saturação e provocaram uma atitude de retraimento por parte de numerosos consumidores.

Este diagnóstico é partilhado, hoje, por grande parte dos profissionais das marcas dentro e fora das empresas. Uma das soluções apontadas para reagir a essa situação e para reavivar a confiança e a disponibilidade dos clientes é a retomada de um diálogo efetivo entre marcas e consumidores.

Na verdade, o discurso das marcas é, comumente, mais um monólogo, uma fala unidirecional, poderosa e evasiva. Ultimamente, ouve-se, com freqüência, a nova palavra de ordem diálogo da marca, que vem pretensamente substituir o discurso da marca, justamente para enfatizar uma atitude mais representativa e mais aberta em relação à mudança, uma intenção de conferir ao consumidor o status de interlocutor ativo em vez de alvo passivo.

Nesse contexto, os espaços comerciais, todos os lugares em que as marcas entram em contato com seu público, adquirem um novo status e tendem a desempenhar um papel-chave nas estratégias de reconquista da confiança dos consumidores e nas tentativas de restabelecer o diálogo - de estabelecer uma conversa - com eles.

As marcas agora entenderam bem isso, elas que nunca se interessaram muito pela distribuição, pela presença calculada nas redes comerciais. Quando o desenvolvimento do e-commerce parecia anunciar o fim dos pontos-de-venda física, um número crescente de marcas "vai para a rua", investe somas consideráveis na recomposição dos espaços, com serviços e pessoal qualificado. Essa tendência é geral, e diz respeito tanto às marcas de produtos como de serviços, estendendo-se igualmente às marcas nascidas na internet, teoricamente destinadas a permanecer no plano virtual.

Sob a ótica de funcionamento das marcas, essa nova idade de ouro do ponto-de-venda destaca uma importante transformação na estratégia de valorização da marca no seio do espaço comercial. Podemos sintetizar essa evolução como a passagem de uma concepção do espaço comercial que propicia a manifestação da marca para a de um espaço comercial que promove o encontro. No primeiro caso, falamos de um esquema de comunicação relativamente clássico (Fig.1).

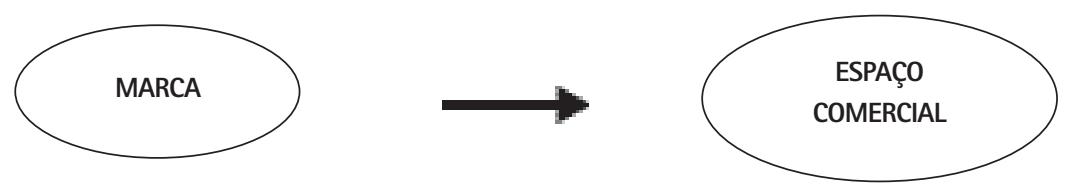

Figura 1 - 0 espaço comercial como dispositivo de comunicação

Da mesma forma que as outras manifestações da marca (a embalagem, o logo, a identidade visual...), o espaço de venda é considerado um dispositivo de comunicação, um lugar de expressão, manifestação dos valores e do universo das marcas. A preocupação, nesse caso, é de tornar a loja imediatamente reconhecivel e marcante, ostentar os valores da marca e concretizá-los em um determinado cenário, num ambiente físico e numa atmosfera, tal qual um grande cartaz afixado com mais ou menos propriedade no cenário urbano. Focando na comunicação de marca, essa abordagem tende às vezes a negligenciar a especificidade do espaço comercial e das dinâmicas que lhe são próprias. Essa estratégia privilegia a fala exclusiva da marca em detrimento do diálogo. 
A necessidade de fomentar a relação entre consumidores e marca favoreceu, assim, a difusão de uma nova abordagem que vê a loja como lugar de encontro e de conversa, de troca, de transformação (Fig. 2). De simples manifestação da marca, 0 espaço comercial se transforma em um lugar onde duas culturas e duas perspectivas, a da marca e a dos consumidores, entram em contato. 0 espaço comercial torna-se, sobretudo, um lugar de transformação em que se passa do abstrato da comunicação a um ambiente concreto, das palavras aos fatos, da promessa de marca à experiência, da fala unidirecional a um verdadeiro diálogo e à possibilidade de uma troca real, de uma interação com os lugares, com a oferta, com os funcionários e, também, com os clientes. Na qualidade de interface entre marca e consumidor, o espaço comercial torna-se, então, a verdadeira fronteira, o momento de verdade da estratégia de marca. 0 que explica a atenção que as marcas vêm dando, ultimamente, aos espaços comerciais e os crescentes investimentos nesse item.

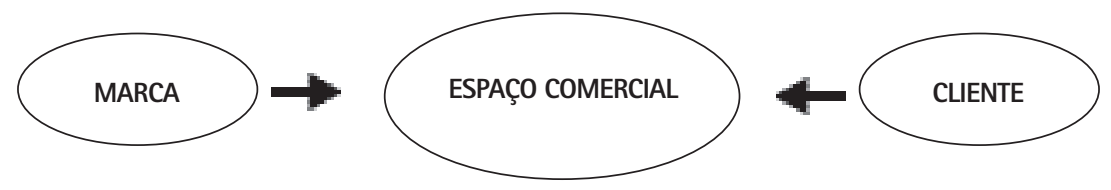

Figura 2 - 0 espaço comercial como momento de regeneração da marca

Esta perspectiva não se coloca no lugar da anterior, pois o ponto-de-venda continua sendo um espaço de exposição dos valores da marca e de sua identidade visual. Ela explora de uma maneira bem mais profunda a verdadeira especificidade dos espaços comerciais, sua natureza de mediadores, sua capacidade de estimular concretamente os clientes e de facilitar a troca real. 0 espaço comercial atual acumula, assim, três dimensões: uma dimensão comercial, que o caracteriza desde sempre; uma dimensão comunicacional, que se desenvolve a partir dos anos 80, e, a partir daí, atingiu seus limites; uma dimensão dialógica, em plena efervescência.

Essa mudança de abordagem se traduz, então, pela pesquisa de novas idéias, de novas pistas, caminhos que possam explorar todo o potencial dos espaços comerciais para aproximar marca e clientes, para desenvolver o diálogo e retomar uma legitimidade que vinha perdendo espaço. Aqui estão cinco tendências, cinco pistas perseguidas pelas marcas, que levam em consideração o novo contexto sociocultural e as novas expectativas dos consumidores.

1. Simplicidade. Num universo de consumo mais complexo e saturado de proposições, a simplicidade passa a ser um valor, desde que não signifique simplismo ou minimalismo, mas que proponha o essencial ou simplifique, selecionando o melhor para o consumidor. A bandeira parisiense de restaurantes Cojean (www.cojean.fr) é um bom exemplo de simplicidade perceptivel nos diversos itens que chamam a atenção nos restaurantes: o espaço, a decoração, a oferta, a forma de exposição dos produtos. Uma outra maneira de simplificar a vida dos clientes é a concebida por Imagine this sold (www.imaginethissold.com), cadeia de bandeiras norte-americanas que concretizou o princípio da Ebay - gestão de leilões -, visando clientes não habituados ao mundo virtual.

2. Relação. As comunidades virtuais na web são fascinantes, mas não substituem a necessidade e o prazer de entrar em contato com outros seres humanos em carne e osso. A marca LG (www.lge.com) transformou as lavanderias dos centros urbanos, lugares sombrios em que, a contragosto, se passa o tempo, em ambientes acolhedores, bar-lavanderia, onde a espera pela roupa lavada se transforma num tempo rico, proveitoso, graças às distrações e à possibilidade de encontrar pessoas. Ing-Direct(http:// home.ingdirect.com) abriu, em diversas capitais européias, cafés onde se pode entrar 


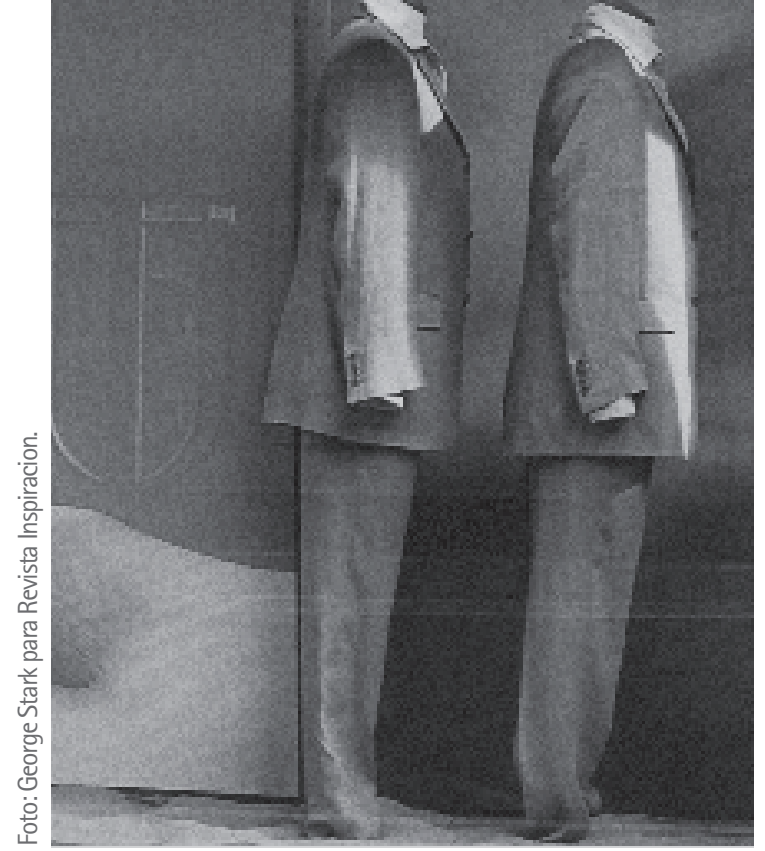

em contato com uma marca que, a priori, se destinaria ao mundo virtual. Projeções mostrando animações sobre bolsa e investimentos levam os clientes a se iniciarem nos mistérios das finanças, numa atmosfera descontraída.

3. Surpresa. Este fator é uma arma poderosa num ambiente de consumo entorpecido e diante de clientes entediados. Eles respondem favoravelmente às marcas que ainda conseguem surpreendê-los e diverti-los. A marca Camper abriu, em Barcelona, um Camper Food Ball (www.camper.com), espaço carregado de humor e de irreverência, dedicado à glória do balão (redondo), onde tudo - produtos, decoração, cardápios - é... redondo! Ainda no universo da alimentação, podemos mencionar o Dylan's Candy Bar (www.dylanscandybar.com), loja, em Nova York, consagrada aos bombons em todas as suas formas e sabores, lugar verdadeiramente mágico, onde a volta à infância é autorizada e até obrigatória. Nessa mesma linha, citamos igualmente o Meow Mix Bar (meowmix.com), em Nova York, o único café no mundo concebido para os gatos e seus donos. No cardápio: croquetes e patês variados (para os gatos), cafés e guloseimas (para os donos) e jogos interativos (para os dois).

4. Estética. A tendência de fundo à estetização da vida cotidiana se estende, a partir de agora, aos espaços comerciais, assegurando um local de destaque para o design ou a arte, a fim de criar lugares únicos, com uma identidade forte e determinada. A estetização permite estabelecer contato com uma clientela exigente, que deseja encontrar nos espaços comerciais uma atmosfera de bom gosto e uma estimulação sensorial agradável. A Illy Gallery, em Nova York, ou a Nissan Gallery, em Tóquio (www.nissan.co.jp), se inserem nesse quadro. No entanto, é preciso ressaltar que a estetização dos espaços comerciais não se limita aos lugares de prestígio e às marcas de luxo, como prova a novíssima loja Apple, de Mahattan.

5. Comprometimento. Para um número crescente de consumidores, dá-se um novo sentido ao consumo, inscrevendo-o numa lógica de responsabilidade e de comprometimento (ético, social, ambiental). A marca Exki (www.exki.be), cuja primeira franquia acaba de ser aberta em Paris, construiu seu espaço comercial e seu projeto de marca a partir de um compromisso, ao mesmo tempo, com a qualidade dos produtos e com a gestão de recursos humanos. Todos os produtos são frescos e provenientes da agricultura biológica. 0 que não é vendido no dia é encaminhado a associações de caridade. A política de emprego prevê um espaço significativo para pessoas com algum tipo de deficiência. A loja Esprit Équo (espritequo.com), em Roma, adota um procedimento que associa estética e comprometimento, para propor uma vasta escoIha de produtos (essencialmente voltados à alimentação e à decoração), cuja origem e ligação com a rede de comércio sustentável é atestada.

Esses poucos exemplos estão, na verdade, longe de esgotar a lista das inovações no universo efervescente da distribuição, mas ilustram bem os esforços das marcas na utilização dos espaços comerciais como "momentos de verdade", situações concretas em que se reinventam modalidades de aproximação e de troca com os clientes. 